\title{
The Product of Language Contact: Sentence Structure in the Hezhou Chinese Dialect and the Amdo Tỉbetan Dialect
}

\author{
Rigzin Wangmo * Gao Xianging **
}

\begin{abstract}
This paper is mainly a comparative study between the Amdo Tibetan Dialect and the Hezhou Chinese Dialect, especially in sentence structure. It is argued that Tibetan possibly influenced the Hezhou Chinese Dialect. In terms of genetic linguistics, the basis of the Hezhou Chinese Dialect is in both Tibetan and Chinese languages. However, the sentence structure of Altaic languages is typologically similar to that of the Hezhou Chinese Dialect.
\end{abstract}

Key words: Hezhou Chinese Dialect, Tibetan

\section{Introduction}

The Hezhou Chinese Dialect is spoken in Linxia Hui Autonomous Prefecture and Gannan Tibetan Autonomous Prefecture of Gansu Province and some of their neighboring areas belonging to Qinhai Province. It is unique not only among the dialects of China's Northwest but also among all the varieties of the Chinese language. Generally speaking, the differences among Chinese dialects are mainly in pronunciation and vocabulary, but not in grammar. However, the striking feature that differentiates the Hezhou Chinese Dialect from Northwest Chinese dialects is its grammar. Such a phenomenon (more difference in grammar than in pronunciation or vocabulary) is not common in the Chinese language.

How did the unique grammar of the Hezhou Chinese Dialect come into being? Is it a variation of Chinese grammar or another grammar completely different from Chinese? All these issues have begun to attract academic attention and inspire a lot of discussions. So far, articles on these issues tend to argue that the grammar of the Hezhou Chinese Dialect is similar to that of Altaic and that it is possibly influenced by Altaic. It is stated that there must have been some historical relationships between the Hezhou Chinese Dialect and Altaic. ${ }^{(1)}$

\footnotetext{
* Rigzin Wangmo: Central Nationality University Press, Beijing, China. E-mail: ningyu4130@yahoo. com.cn.

** Gao Xiangjing: School of Tourism and Foreign Languages, Tibet Univeysity, No. 36 Jiangsu Road, Lhasa 850000, Tibet, China. E-mail: gaoxj2005@lzu.cn.

(1) Ma Shujun (1984) commented on the uniqueness of the Hezhou Chinese Dialect's grammar in National 


\section{The Product of Language Contact: Sentence Structure in the Hezhou Chinese Dialect and the Amdo Tibetan Dialect}

The grammar of the Hezhou Chinese Dialect differs from general Chinese grammar but the fundamental grammatical structure of the Hezhou Chinese Dialect is quite similar to Tibetan. Through a special investigation of historical relationships between the Tibetan people and the Hezhou area, we hold that it is quite possible that Tibetan language had a historical influence on the Hezhou Chinese Dialect.

First, as viewed from the history of the Hezhou area, in the slave society of Xia, Shang and Zhou Dynasties, the inhabitants of the Hezhou area were mainly Qiang nomad tribes (Qiang was an ancient national minority in China). After the Qin Dynasty united China in $221 \mathrm{BC}$, the government established Baohan County in today's Linxia City, stationed troops and immigrated inhabitants, making Hezhou area the westernmost frontier fortress of the Dynasty. During the Han and Wei Dynasties (206 BC-265 AD), Hezhou was the place of contention between minority tribes headed by the Qiang and the Central Plains emperors. In the Tang Dynasty (618-907), the Tubo rose and established a regime in the Qinghai-Tibetan Plateau. Gradually, its influence extended as far as east of Gansu Province. From Emperor Dezong (780-805) to the whole Five Dynasties (907-960), the Hezhou area was occupied by the Tubo regime for a long time. In the first hundred years of the Song Dynasty (960-1279), the area was under the direct command of a feudal separatist rule called Rgyal-sras, which mainly consisted of Tibetan people. In the Yuan Dynasty (1271-1368), the royal high pacification commissioner's office for the Tubo and other areas was set up in today's Dongxiang County, Linxia City. Most of the pacification commissioners were Tibetan. For a long time, the Hezhou area was an area where people of Han and Tibetan nationalities lived together. All previous dynasties continuously moved Han people to the Hezhou area to garrison the frontier where Tibetans actually ruled. As we can see, the area is a place where people of Han and Tibetan nationalities have lived together for a long time.

In the Hezhou area, Altaic is spoken by ethnic groups of Dongxiang, Bao'an, Salar, Tuzu, etc, whose history dates back to the Yuan Dynasty. Moreover, most of them live far from the centre of the area. It is thus obvious that their history in the Hezhou area is much later than that of the Tibetan people. Even in their ethnic origins, there must have been some Tibetan people who inhabited the area where they live now. ${ }^{(1)}$ It is quite possible that the Hezhou Chinese Dialect had come into being and become the main communicative mean

Languages. He made a comparison between the Hezhou Chinese Dialect and Altaic. In view of some similarity between the two languages, he assumed a certain historical relationship between them. However, he also noticed that there were few local people speaking Altaic and their history was not very long. As a result, he also doubted the influence of Altaic on the Hezhou Chinese Dialect.

(1) Cf. A Survey of Linxia Hui Autonomous Prefecture (1986), Concise Historical Sketch of Dongxiang Ethnic Group (1984), Concise Historical Sketch of Bao'an Ethnic Group（1984）. 
between Han and Tibetan people in the area before those ethnic groups were formed.

\section{Similarity in syntax}

$\mathrm{S}-\mathrm{O}-\mathrm{V}$ pattern is the common sentence structure of Tibetan and the Hezhou Chinese Dialect, in which some case auxiliaries and other auxiliary words are added to demonstrate different grammar meanings and denote grammar relations of sentence elements. The position and the grammar meaning of these case auxiliaries and auxiliary words are correspondent in Tibetan and the Hezhou Chinese Dialect. Also, we can find some rules of change between them in pronunciation. The following are some comparative examples of Tibetan and the Hezhou Chinese Dialect given by the authors, who specially chose languages they are familiar with, namely, the Xiahe Tibetan Dialect of Gannan Tibetan Autonomous Prefecture and the Hanjiaji Chinese Dialect of Linxia Hui Autonomous Prefecture, which are marked by "[T]" (Amdo Tibetan Dialect) and "[H]" (Hezhou Chinese Dialect), respectively. Generally speaking, the additional part of the Hezhou Chinese Dialect that denotes the grammar meaning is in light tone, so its intonation is not marked in the following examples. To make things easier, some conventional Tibetan grammar terms are also borrowed in this paper.

\subsection{Case Auxiliaries}

\subsubsection{Agentive Auxiliaries}

This form is attached to nouns, pronouns or noun phrases, indicating the person or the thing that functions as agent. For example,

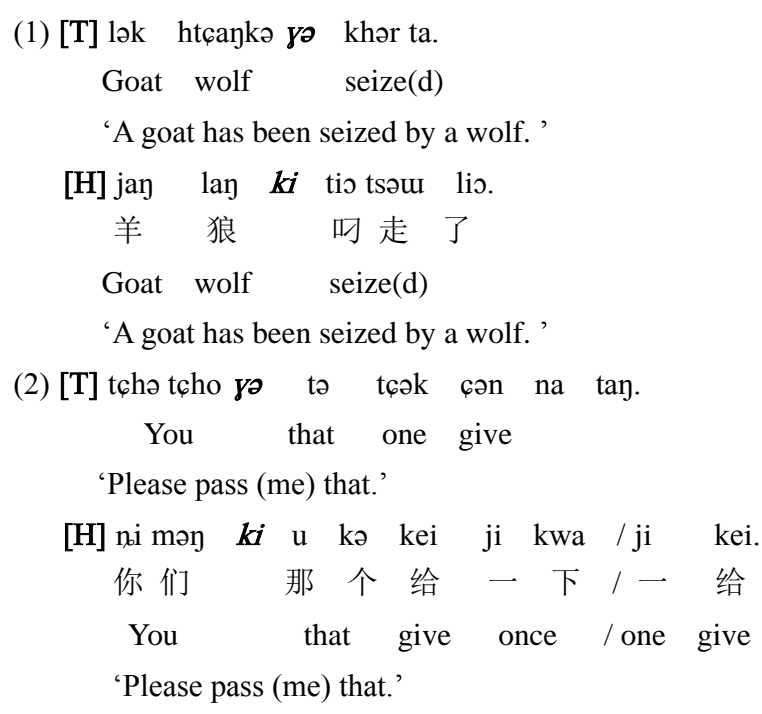

According to the derivation rules of Amdo Tibetan pronunciation, yə, kə, ngə are all the derivations of $k i$. 
The Product of Language Contact: Sentence Structure in the Hezhou Chinese Dialect and the Amdo Tibetan Dialect

In Tibetan, a noun ending in a vowel can be directly followed by an agentive case to indicate it is agent, which is especially represented by the singular form of a personal pronoun. For instance, $\eta a(\mathrm{I})-\ldots$ tcho (you ) in the above examples can be directly followed by htcan ki and tcho tcho instead of adding the case auxiliary " $y$ ".

In the Hezhou Chinese Dialect, the agentive auxiliaries can sometimes be omitted if no misunderstanding occurs as a consequence.

2.1.2 Case Auxiliaries of State, Means, Instrument and Material

In Tibetan, the phonetic representation of this kind of case auxiliary is usually the same as with agentive auxiliaries.

(3) $[\mathrm{T}]$ hnok $\boldsymbol{k} \boldsymbol{\boldsymbol { \theta }}$ hte.

Eyes look

'Look with your eyes.'

[H] nan tçวn la khan.

眼 睛 看

Eyes look

'Look with your eyes.'

(4) [T] ndə mar $k \boldsymbol{k}$ le nə rə.

This butter make

'This is made of butter.'

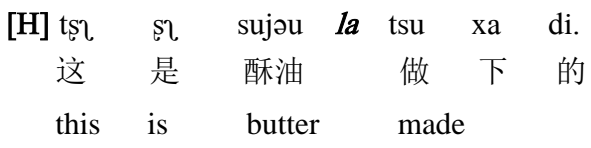

'This is made of butter.'

Conventional Tibetan grammar holds that the phonetic representation of case auxiliaries describing means, instrument, etc. is the same as in agentive auxiliaries. The same is true in the Modern Amdo Tibetan Dialect. However, in some written materials, the phonetic representation of the case auxiliary "kə" can also be replaced with "la". For example, there is an episode in a Tibetan fable The Stories of a Monkey and a Bird:

(5) [T] khoy hdab tchags lchags $\boldsymbol{l a}$ bzos pa min, ya spruefu mar $\boldsymbol{l a}$ bzos pa min.

He bird iron make not, I monkey butter make not

'They, the birds, are not made of iron and we, the monkeys, are not made of butter.'

\subsubsection{The Case Auxiliary gis and Its Variations}

Apart from the two case auxiliaries we have discussed, there is another one that is attached to words or phrases describing cause. This grammatical function can find its correspondence in $l \boldsymbol{a}$ in the Hezhou Chinese Dialect.

(6) [T] hnam wap $\boldsymbol{n e}$ shoy ne ma wa ta. 


\section{Rigzin Wangmo Gao Xiangjing}

rain fall go not

'(Implied subject) didn't go because of the rain.'

[H] ju xa tş mə tçhə xa.

雨 下 没去下

rain fall not go

'(Implied subject) didn't go because of the rain.'

If words of cause are added, the sentence can be

(6') [T] hnam wap no htap $\boldsymbol{k} \boldsymbol{\partial}$ shon ne ma wa ta.

rain fall cause go not

'(Implied subject) didn't go because of the rain.'

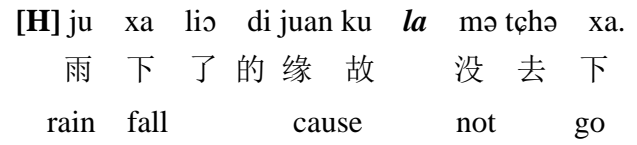

'(Implied subject) didn't go because of the rain.'

If words denoting cause are removed, the sentence can be

(6") [T] hnam wap no yo shoy ne ma wa ta.

rain fall go not

'(Implied subject) didn't go because of the rain.'

$[\mathrm{H}] \mathrm{ju}$ xa lio di $\mathbf{l a}$ mə tçhə xa.

雨下了的没去下

rain fall not go

'(Implied subject) didn't go because of the rain.'

2.1.4 Case Auxiliary of Coordinate Predicates, Cause, Direction and Time

This kind of case auxiliary is attached to verbs or verb-object structures to refer to cause and coordinate predicates. On the other hand, it can be attached to nouns, interrogative words or demonstratives to describe direction and time. In Tibetan, its phonetic representation is "ne" while in the Hezhou Chinese Dialect it is "tşə", denoting cause and coordinate predicates, and "ta", depicting cause and time.

(7) [T] hnam wap $\boldsymbol{n e}$ shoy ne ma wa ta.

rain fall go not

'(Implied subject) didn't go because of rain.'

[H] ju xa tso mə tçhə xa.

雨下 没去下

rain fall not go

'(Implied subject) didn't go because of rain.'

(8) [T] şay ya shoy ne kon ndzə zək מze ne wə jon.

street go clothes one buy back 
The Product of Language Contact: Sentence Structure in the Hezhou Chinese Dialect and the Amdo Tibetan Dialect

'(Implied subject) went to the street and came back with a piece of clothes he bought.'

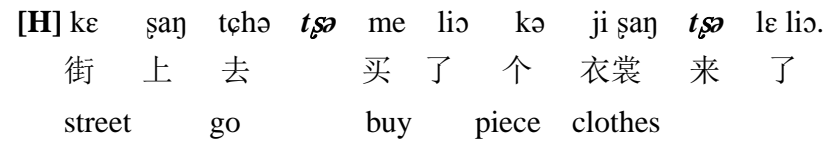

'(Implied subject) went to the street and came back with a piece of clothes he bought.'

(9) [T] tcho kay ne joy nə?

you where come

'Where are you from?'

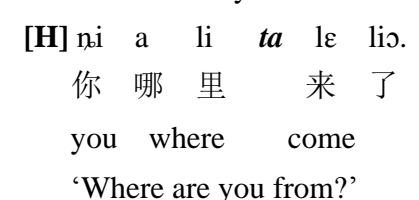

(10) [T] na nay ne joy ma nay.

last year come not once

'(Implied subject) hasen't been here since last year.'

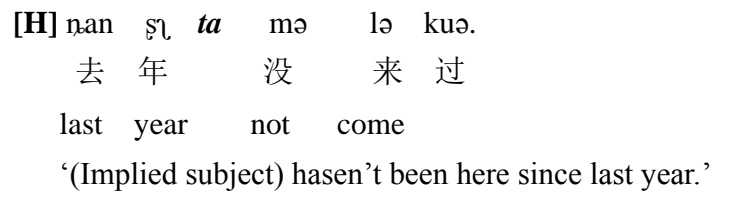

The case auxiliary that describes time combined with "ke" denotes the same meaning both in Tibetan and the Hezhou Chinese Dialect. In Tibetan, the consonant / $\mathrm{k} /$ sound is assimilated into the foregoing nasal as "ng". For instance,

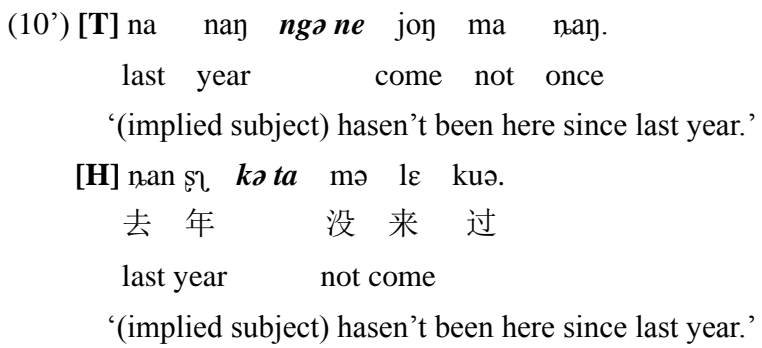

The case auxiliary of time "ne" means "since". Its opposite meaning "until" can also be found both in Tibetan and the Hezhou Chinese Dialect, the phonetic representations being "thək she" in Tibetan and "tha la" in the Hezhou Chinese Dialect. (According to Amdo Tibetan grammar, thok she < thugs su is derived from "thugs la". In Amdo and other places, a simple "la" might be spoken.)

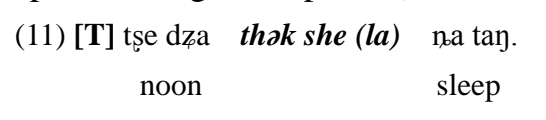

'(implied subject) slept until noon.' 


\section{Rigzin Wangmo Gao Xiangjing}

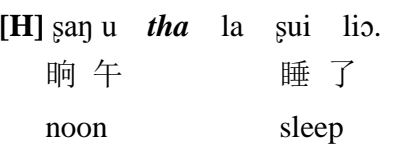

'(implied subject) slept until noon.'

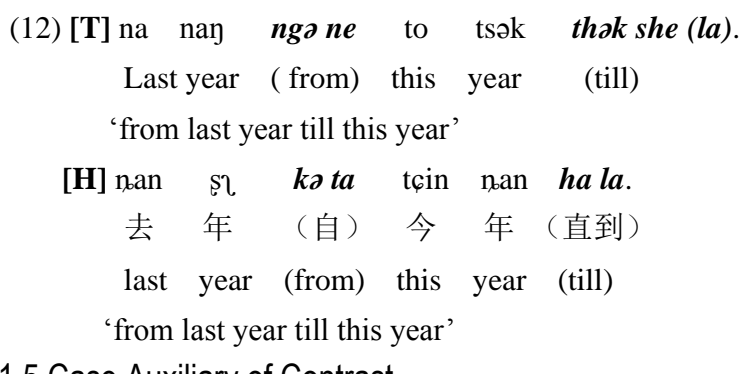

\subsubsection{Case Auxiliary of Contrast}

The word before this case auxiliary is the object to be compared with. Its phonetic representation is "le" in Tibetan, derived from "las" . In the Hezhou Chinese Dialect, it is "la sl", which is obviously similar to "las". For example,

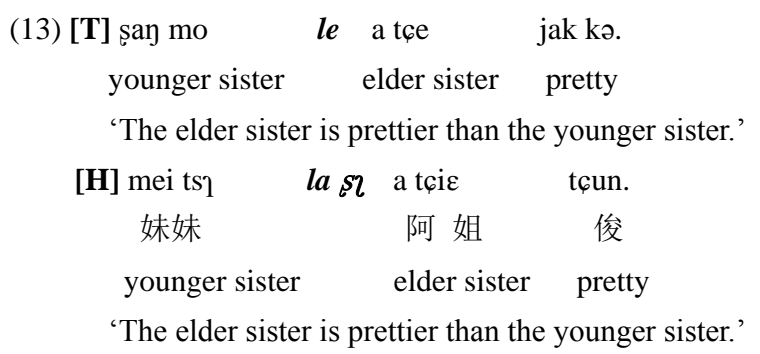

In Tibetan, the same meaning can also be expressed by combining "hte" (look) with "la", to form a new structure of "... .la hte yə". Its correspondent form "...la khan ş" can also be found in the Hezhou Chinese Dialect . For example,

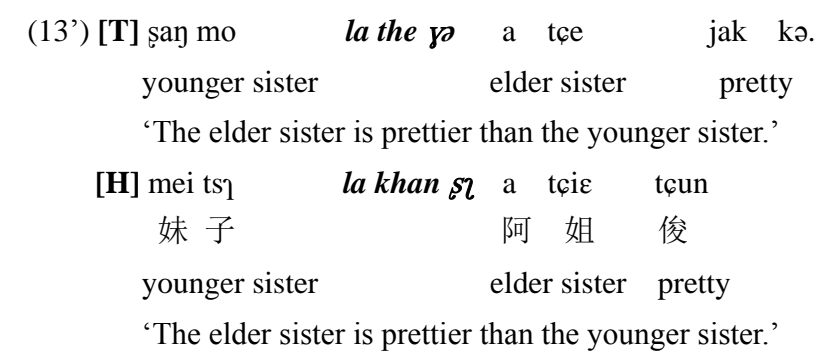

\subsubsection{Case Auxiliary of Patient}

The phonetic origin of this kind of case auxiliary is " $l a$ ", which has many variations with the tail vowel of the last syllable in Ambo Tibetan pronunciation. It is closely attached to the singular form of a pronoun both in Tibetan and the Hezhou Chinese Dialect. If we use surface and depth to describe pronunciation, vocabulary and grammar, the surface form of 
The Product of Language Contact: Sentence Structure in the Hezhou Chinese Dialect and the Amdo Tibetan Dialect

the Hezhou Chinese Dialect is that of Chinese, but affected by non-Chinese deep structure, because the first and second person singular in the Hezhou Chinese Dialect have fallen into the case category.

The first person pronoun "yə" (I) and the second person pronoun "n,i”" (you) have double meanings: one refers to the original form, while the other refers to the agentive case of pronoun, distinguished from their patient case "ya" and "na". For example,

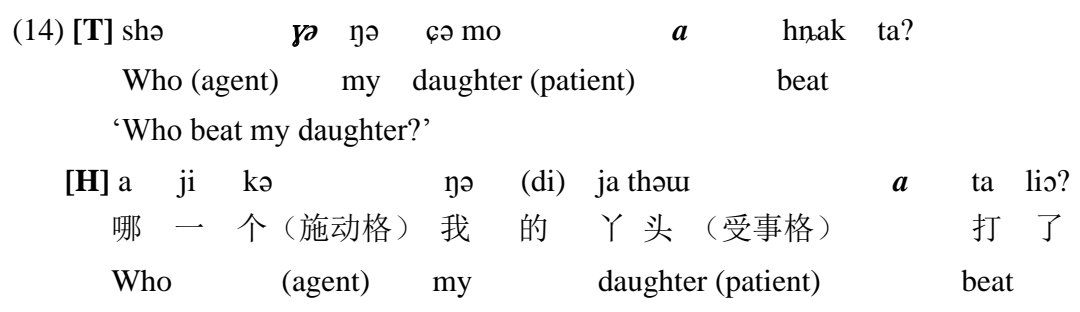

'Who beat my daughter?'

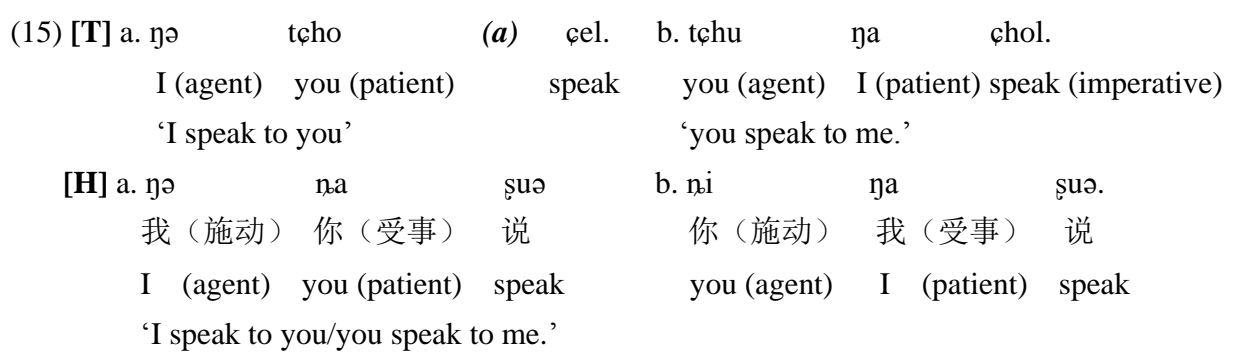

If the predicate verbs in Tibetan mean "to exist", "to have", etc., the subject will be in patient form. The same is true in the Hezhou Chinese Dialect. For example,

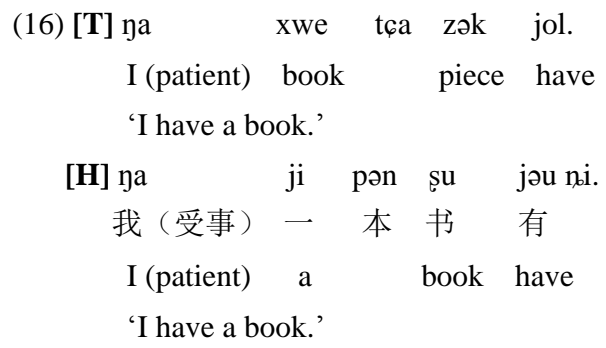

If there are other verbs apart from the predicate verb that mean "to exist" and "to have", the subject can appear both in agentive case and patient case and the meaning remains the same. For example,

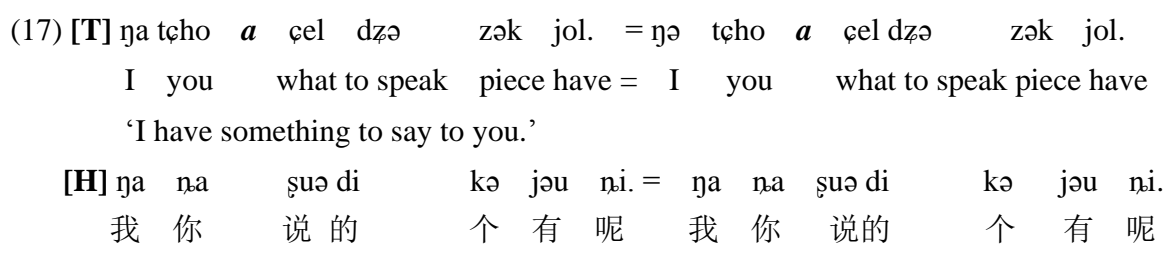




\section{Rigzin Wangmo Gao Xiangjing}

I you what to speak piece have = I you what to speak piece have

'I have something to say to you.'

In sentences without the predicate verbs "to exist" and "to have", the agentive case and the patient case cannot be interchanged, for the meaning will be changed into the patient. For example,

$$
\begin{aligned}
& \text { (18) }[\mathbf{T}] \text { a. yə sa } \text { b. ya sa } \\
& \text { I eat eat me } \\
& \text { 'I eat.' 'eat me.' } \\
& \text { [H] a. yə tșh } \quad \text { b. ya tșh } \\
& \text { 我吃我吃 } \\
& \text { I eat eat me } \\
& \text { 'I eat.' 'eat me.' }
\end{aligned}
$$

2.1.7 Case Auxiliary of Direction and Place

The phonetic origin of this kind of case auxiliary is "la" and its variations. In the Hezhou Chinese Dialect, the case auxiliary of direction is usually omitted, but the phonetic representation of the case auxiliary of place is the same as that in Tibetan.

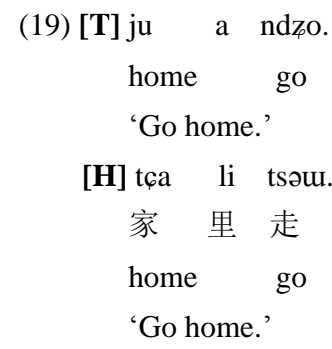

(20) $[\mathrm{T}]$ nde $\quad$ (Łndə) htsok.

here sit (imperative)

'Sit here.'

$$
\begin{array}{ccc}
{[\mathbf{H}] \text { tş tha }} & \boldsymbol{l a} \boldsymbol{a} & \text { tsuoxa } \\
\text { 这 } 儿 & \text { 坐下 } \\
\text { here } & \text { sit down }
\end{array}
$$

'Sit here.'

2.1.8 case auxiliary "la" and its variations

In Tibetan, the case auxiliary " $l a$ " and its variations are used frequently and they can also be used in the form of adverbial structures combined with other phrases in a sentence. This grammatical use can also be found in the Hezhou Dialect. For example,

$$
\begin{gathered}
\text { (21) }[\mathbf{T}]^{\mathrm{P}} \mathrm{o} \text { tcho nam nbe ndzo. } \\
\text { we together go } \\
\text { 'We go together. }
\end{gathered}
$$


The Product of Language Contact: Sentence Structure in the Hezhou Chinese Dialect and the Amdo Tibetan Dialect

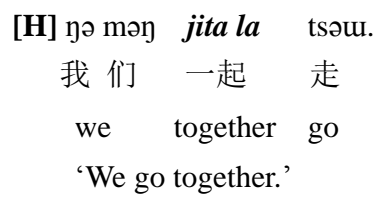

\subsubsection{Case Auxiliary of Defining}

The phonetic representation of the case auxiliary of defining is "na" in Tibetan and "s?" in the Hezhou Chinese Dialect. It seems that "si" is derived from the Chinese defining word "shi". However, its grammatical function is the same as the Tibetan defining case auxiliary "na". For example,

(22) [T] yə hte $\boldsymbol{n a}$ rək kə.

I think alike

'I think (implied subject) are alike.'

[H] yo khan šchan ni.

我看象呢

I think alike

'I think (implied subject) are alike.'

\subsection{Other Case Auxiliaries}

In the above section, we have discussed the corresponding case auxiliaries which denote the relationships between sentence elements in Tibetan as well as in the Hezhou Chinese Dialect. Apart from these, there are some modals and other auxiliaries whose number and grammatical functions are both correspondent in Tibetan and in the Hezhou Chinese Dialect. For example,

\subsubsection{Command Modals}

In Tibetan, the command modal " $\mathrm{\gamma} \partial$ chək" is attached to the end of a sentence to refer to the meaning of "letting....do...". In the Hezhou Chinese Dialect, "ki" or "di" or "ki di" refers to the same meaning. For example,

(23) [T] to ndzo go chok.

he go

'Let him go!'

[H] u kə tsəu $\boldsymbol{d i}(\boldsymbol{k i}) / \boldsymbol{k i} \boldsymbol{d i}$.

他走

he go

'Let him go!'

\subsubsection{Modals of Imperative}

In Tibetan, the imperative mood is expressed by adding " $\mathrm{x}$ chək za" to the end of a sentence. In the Hezhou Chinese Dialect, "ki şa" or "di za" describes the same meaning. For example, 


\section{Rigzin Wangmo Gao Xiangjing}

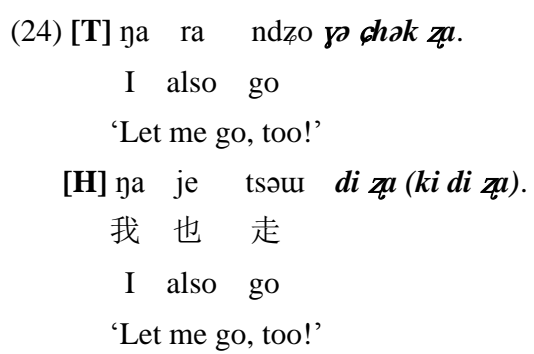

2.2.3 Auxiliaries of Reported Speech

Tibetan uses "zer" to indicate reported speech while the Hezhou Chinese Dialect uses "š". The meaning of "zer" in Tibetan is "to say", while "sน" in the Hezhou Chinese Dialect is the variation of "suə" (say). So, "ş" can be replaced by "suə". For example,

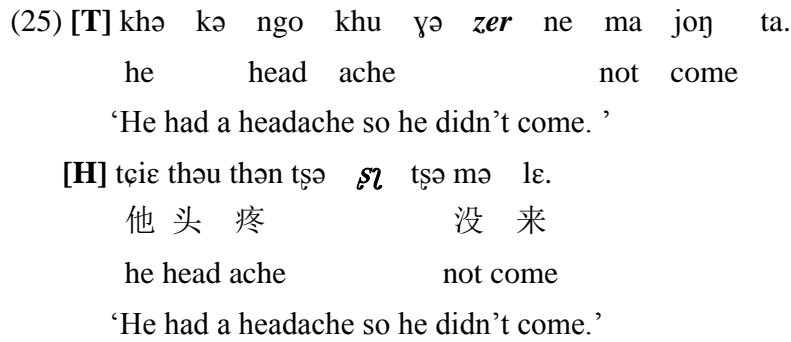

This form can also be used to judge a thing that is about to happen. For example,

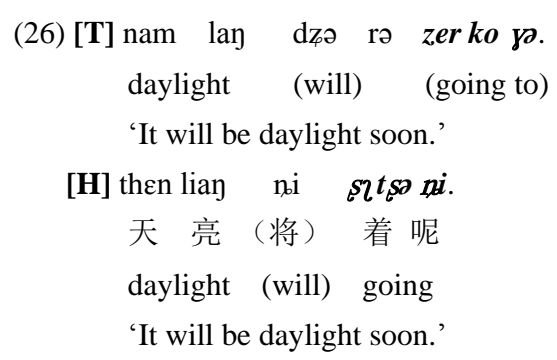

\subsection{Word Order and Other}

\subsubsection{Word Order}

The word order of the Hezhou Chinese Dialect is different from the Chinese fixed S-V-O word order, but it is the same as the word order of Tibetan: S-O-V. For example,

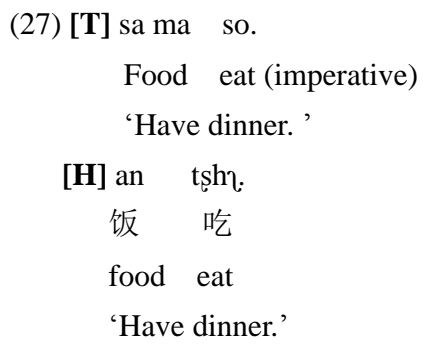


The Product of Language Contact: Sentence Structure in the Hezhou Chinese Dialect and the Amdo Tibetan Dialect

(28) [T] ya go dzak kə ndzo.

I door close go

'I'll go close the door.'

[H] yə məy guan tçhə.

我门关去

I door close go

'I'll go close the door.'

2.3.2 Usage of Defining Word

In Tibetan, the defining word is usually preceded by a predicative. is the same is true in the Hezhou Chinese Dialect. For example,

(29) [T] sə jən? ya jən.

who is I am

'Who is it? It is me.'

$[\mathbf{H}]$ a ji kə sq ni? yə sq ni.

哪一个是呢我是呢

which one is I am

'Who is it? It is me.'

2.3.3 Means of Expressing the Causative

Tibetan verbs have two causative forms: one is inflectional and the other is analytic. The Hezhou Chinese Dialect has no inflections, but it has an analytic form of verbs, whose structure is the same as in Tibetan. For example:

(30) [T] yo tsha yə zok tay.

shy

'It makes me shy.'

$[\mathbf{H}]$ cəu xa di ni.

羞下

Shy

'It makes me shy.'

(31) [T] ngo jək khor kə zək tap.

head dizzy

'It makes me dizzy.'

$[\mathbf{H}]$ jun xa di ni.

晕下呢

dizzy

'It makes me dizzy.'

2.3.4 Conjunctions

The usage of conjunctions in the Hezhou Chinese Dialect is the same as in Tibetan and 


\section{Rigzin Wangmo Gao Xiangjing}

the phonetic representations are similar to each other. For example:

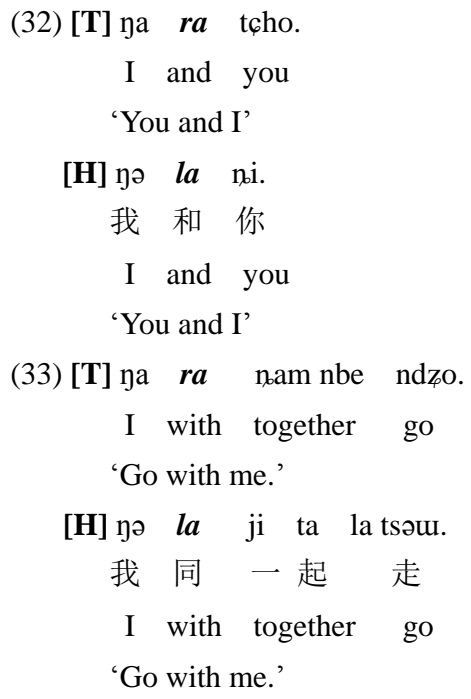

\subsubsection{Determiners}

The usage of a determiner in the Hezhou dialect is the same as in Chinese. It is put before its head noun. However, if it is used in generic reference, like in Tibetan, it should be put behind the head noun. For example:

$\begin{array}{ccccc}\text { (34) [T] ndə na } & \text { sa dzə } & \text { zək } & \text { ra } & \text { me } \\ \text { here } & \text { food } & \text { piece } & \text { even not }\end{array}$

'Not even food is ready here.'

[H] tş̧ li tş̧ר di $\boldsymbol{k} \boldsymbol{\partial}$ təu mə jəu.

这里吃的个都没有

here food piece even not

'Not even food is ready here.'

In addition, the Chinese " $\mathrm{V}-\mathrm{V}$ " refers to a temporary behaviorwhile the Hezhou Chinese Dialect uses "-V" to refer to a temporary behavior, which is the same usage as in Tibetan. For example:

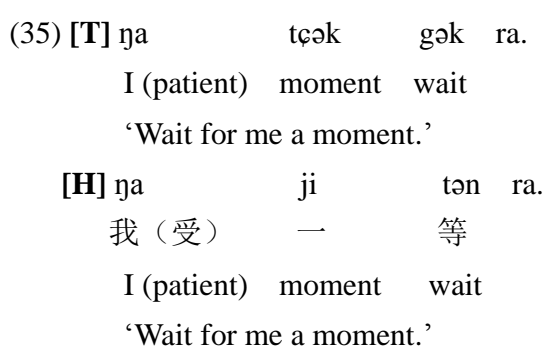


The Product of Language Contact: Sentence Structure in the Hezhou Chinese Dialect and the Amdo Tibetan Dialect

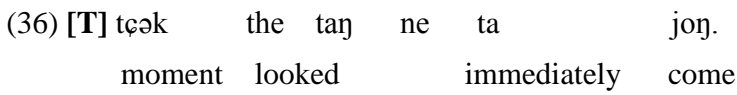

'Have a look, and then I will come immediately.'

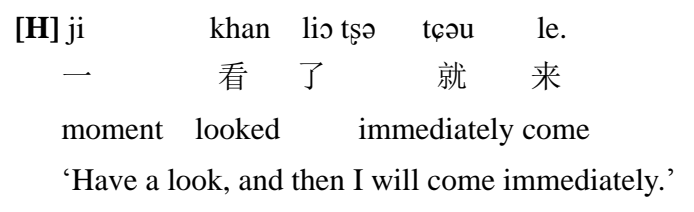

\section{Analysis for the origin of such phenomena}

Through the above given comparative analysis, we can see that the main sentence structure of the Hezhou Chinese Dialect is extraordinarily similar to that of Tibetan, not only in the grammatical models but also in the phonetic representation. The Han and Tibetan people lived together exclusively for a long time in history. In view of this, we can make a bold assumption that under the special historical conditions of that time, Chinese, as a new and borrowed language, had a certain impact on the local vernacular language, through forced assimilation or natural penetration.

However, this impact has only affected the surface structure of the vernacular language instead of the deep structure which is firmly established and unchanged. Through a long interaction, the Hezhou Chinese Dialect eventually came into being, as a new lingua franca mixing Tibetan sentence structure and Chinese pronunciation and vocabulary. In terms of genetic linguistics, the basis of the Hezhou Chinese Dialect is established in both the Tibetan language and the Chinese language. Nevertheless, the fact that Altaic and the Hezhou Chinese Dialect are similar in sentence structure should be incorporated in typological study. It is certain that we cannot exclude the possibility of the influence of Altaic on the Hezhou Chinese Dialect, for the Hezhou Chinese Dialect is the communication mean used by all the people who belong to different ethnic groups.

\section{References}

Group of Authors of A Survey of Linxia Hui Autonomous Prefecture. 1986. A Survey of Linxia Hui Autonomous Prefecture. [M] Lanzhou: Gansu Nationalities Press.

Group of Authors of Concise Historical Sketch of Bao'an Ethnic Group. 1984. Concise Historical Sketch of Bao'an Ethnic Group. [M] Lanzhou: Gansu Nationalities Press.

Group of Authors of Concise Historical Sketch of Dongxiang Ethnic Group. 1984. Concise Historical Sketch of Dongxiang Ethnic Group. [M] Lanzhou: Gansu Nationalities Press.

Ma Shujun. 1984. Hezhou Chinese Dialect and Altic language [J] Minzu Yuwen (Chinese Language). No.2. 